\title{
"Fresher Than You": Commercial Use of YouTube-Native Dance and Videographic Techniques
}

Alex Harlig, The Ohio State University

\begin{abstract}
This article focuses on four examples of commercial use of web-native and amateur video and dance aesthetics, including music videos and videos promoting clothing brands, and how corporate logics have adopted these genres and caused them to adapt in turn. Commercial use both subsumes and broadcasts the innovations of dance communities, amateur filmmakers, and subcultural entrepreneurs. At the same time, I argue that the possibility of greater self-control for the making and distributing of filmed popular dance in the social media context renders commercial mediation of popular dance more desirable to many communities of practice. Through looking at generic and technical attributes of the examples, I address the continued rhetorical power of binaries like amateur and professional, commercial and participatory, categories the reality of dance in social media in fact undermine. The commercial use of web-native videographic and dance styles is complicated by new opportunities for representation, remuneration, and creative control that come with the new platforms and modes of production. These music videos and advertisements transmit social media-native movement, videographic, and promotional techniques, but still do so within longstanding infrastructures that primarily benefit those with preexisting economic and cultural capital, and along lines of class and race.
\end{abstract}

Keywords: YouTube, Popular Dance, Music Video, Advertising, Labor

In November 2014, almost ten years after the founding of the video-sharing platform YouTube, global popstar Beyonce冈 released the music video "7/11." Seemingly shot on a whim with an iPhone at a hotel, the video combines the visual hallmarks of amateur YouTube video with the star power, strategy, and sound of a studio-produced music video. Beyoncé's friends are better looking, her lodgings nicer, and her view countnow over 400 million-higher than what is typically represented in iPhone videos posted online, but the cinematography, choreography, and costuming come directly from aesthetics developed in YouTube and social media-native videos. Reflecting a process commonly observed in other realms of popular culture, popular dance and screen genres begin in specific, usually subcultural communities and economies, but as they circulate, larger brands and media outlets adopt and monetize them. Dance forms with local histories and identities are always cooptable by larger structures of power but The International Journal of Screendance 9 (2018).

() 2018 Harlig. This article is published under a Creative Commons Attribution 4.0 International License (https:/creativecommons.org/licenses/by/4.0/) 
in excess of them, such that new genres, movements, and economies are constantly emerging and circulating online, building on and pushing back against widely circulating images.

Commercial use and collaborations both subsume and broadcast the innovations of dance communities, amateur filmmakers, and subcultural entrepreneurs. These music videos and advertisements transmit social media-native movement, videographic, and promotional techniques, but within longstanding infrastructures that primarily benefit those with preexisting economic and cultural capital, whether brands, celebrities, or along lines of class and race. I argue that the social media context of mediation, and the possibility of self-controlled outlets for the making and distributing of filmed popular dance, changes the reception for commercial mediation of popular dance by communities of practice.

In her foundational text Dancing on the Canon, Sherril Dodds asserts the need for scholars to focus on "the contesting of power relations between the commercial industries that seek to produce and disseminate popular dance and the participants in popular dance who create locally articulated practices." ${ }^{11}$ In this article, I balance these competing interests through an analysis of the cyclical exchange and intertwining of perpetuation and innovation, subculture and pop culture, amateur and professional, the subversive and the neoliberal, that characterize YouTube, Internet genres, and popular dance. In particular, I investigate the adaptation of Internet dance and video aesthetics by commercial music videos and advertisements as a component of the complex and always racialized economy of popular dance.

The corporate use of online participatory culture has been studied and critiqued as part of recent interests in convergence culture, prosumers, and the intellectual property rights of social media users. I I want to particularize these issues by examining a range of screen and Internet genres in which dance occurs, and how they are being interwoven by various actors and to what effect. In the preface to the 2013 volume Amateur Media, the editors note "our frameworks for understanding contemporary amateur media and their consequences remain far less well developed than the objects of our interest." ${ }^{\prime 3}$ Part of the difficulty is the wide range of modes, platforms, and relations to capital within which such media exists. Given the always already commercial nature of these platforms, Burgess and Green propose a shift in "concern away from the false opposition between market and non-market culture, toward a concern with the tensions that arise when corporate logics have to contend with the unruly and emergent characteristics of participatory culture." ${ }^{\prime 4}$ In order to begin developing frameworks in line with the complex reality of popular dance on the Internet, and how corporate logics have adopted them and caused them to adapt in turn, this article focuses on four examples of commercial use of web-native and amateur video and dance aesthetics. There are a range of web-native video genres, popular dance genres, and funding and production structures among them. 
These examples are, briefly: Beyoncé's " $7 / 11$, "5 a 2014 music video that uses amateur elements to create a feeling of proximity and intimacy, but which was backed by a record company and released in promotion of an album as well as merchandise. The "AZ of Dance," ${ }^{6}$ also from 2014, is a commercial-as-dance-video circulated exclusively online, with web-native dance forms, composition, and premise, promoting new media company i-D, and the Diesel Jeans clothing brand. "\#ICAN Kick It" is a 2017 YouTubenative concept dance video released by YouTube presence lan Eastwood and sponsored by the clothing company American Eagle. Finally, I will discuss the fall 2017 music video for the remix song "Mi Gente ft. Beyoncé," ${ }^{8}$ which uses actual amateur video in a fan-like mashup to promote the star personas, music, and fame of the musicians involved, as well as to raise money for disaster relief in Mexico and the Caribbean. ${ }^{9}$ I employ these examples to theorize and illustrate what I consider three crucial areas of investigation for dance on the Internet: 1) the cycle of innovation within the popular domain, and its absorption into large scale systems of capital; 2) how the creation of new genres also creates new statuses for and categorizations of people involved with them; and 3) the continued rhetorical power of categories like amateur and professional, commercial and participatory-binaries that the reality of dance in social media in fact undermine.

Before delving into my analysis of how these videos show the ways advertising has taken up new modes of production and representation, I first lay out my terms of categorization, followed by a description of each video and how it exemplifies aspects of web-native production. Finally, I consider the complexities of the desire for and access to commercial funding, and how this reflects and shifts historical relations between popular dance and capital.

\section{Establishing Terms: Commercial, Professional, Amateur, Web-native}

I define these terms here specifically within the social media context, though the terms, as with the content they describe, are always in tension with the larger media landscape and economy.

With the term "commercial," I refer to videos made by legacy media companies and/or videos that promote a good or service. Dance is having a prolonged moment in the public imaginary in legacy media forms like television and movies as well as online. Because of this, it features frequently in advertising, especially for wearable items and products targeted at teens and young adults. However, not all commercial content is identifiable as advertising. Two of the examples I consider, Beyoncé's "7/11" and "Mi Gente ft. Beyoncé," are music videos. While there have been innovations and changes in music video production and content since the advent of YouTube, ${ }^{10} \mathrm{I}$ consider the music video a legacy media genre. Not only were the content and formal properties established before social media; contemporary production and funding structures 
remain tied to record company standards and budgets. Also, while the focus of this article is the use of YouTube-native and amateur elements, not all commercial content found on YouTube and other social video platforms is web-native; advertisements made for broadcast television, or in that style, also circulate online.

The terms "professional" and "amateur" are more complicated; the perceived 'quality' or 'professionalism' of a video is both visual as well as structural. For viewers on the YouTube platform, the professionalism of a video might be communicated through verified accounts, sponsorships, pre-roll advertisements, or the creator being on brands' PR lists for products or travel. Live tours and channel-branded merchandise, high view counts, well-known subscribers, and interaction with the official YouTube Spaces all help to build the appearance of legitimacy. Aesthetically, professionalism also manifests in the 'production values' of newer and constantly improving cameras, lights, sets, costumes, and rigs; the use of drones or helicopters in travel vlogs or concept videos; collaborations with other popular YouTubers, and scripted material. However, these videos and their creators may still not be considered 'professional' in the larger sphere of legacy media and its viewers, and many seek further opportunities there while maintaining their YouTube presence.

By contrast, amateurism within social media distinguishes from those for whom content creation is a career or active pursuit. This distinction moves beyond the description offered by Hunter et. al: "non-salaried, non-specialist and untrained in media production,"11 as those attributes also hold for many of the top earners of social media video. Rather, it refers to video that might be taken off the cuff, posted outside of a schedule, made as a practice of fandom, or disseminated without remuneration. Media scholar James Meese points to the condition of amateur video circulation as a defining feature, noting that "[i]n contrast to professional content creators, amateurs often have fewer resources on hand to protect their copyrighted work and are also challenged by a pervasive online rhetoric that suggests that popular content essentially 'belongs to the Internet."'12 Notably, the division between professional and amateur dovetails with distinctions between dance forms as art forms or as vernacular practices, distinctions that, as Gottschild, Manning, and Kraut, ${ }^{13}$ have shown, historically rendered black cultural production as though it belongs to the larger cultural sphere. However, as we will see below, the particularities of funding and content creation online challenges the divisions and implicit hierarchies between amateurism and professionalism.

Because there are stratifications within social media video production that remain opaque to many outside of it, "web-native" or even "YouTube-native" videos and genres may be more useful categories than amateur and professional to understand the complexity of the ways genre and commercial use intersect for popular dance. The term "web-native" encompasses all those "user generated" videos by "content creators," or people who focus on making Internet content, predominately on YouTube-but also on social media platforms such as Instagram, Snapchat, and Facebook-regardless of 
their level of quality or economic support. Creators of web-native content frequently perform many tasks that would be specialized in larger projects: choreographing, directing, and video editing, in addition to dancing, for example. The term also refers to forms of cultural production that simply did not exist prior to the current video hosting platforms. ${ }^{14}$ Web-native content can be produced by amateurs, as implied in the designation of "user-generated content" as that which differentiates social media from broadcast media, but established companies also use YouTube and other platforms to market their products to different consumers than legacy media afford.

YouTube thus brings commercially and professionally produced content in direct contact with amateur content, blurring the boundaries between these categories, as well as blurring distinctions between web-native and legacy content. The next section contains a description of each video and how it exemplifies particular aspects of webnative video as they play out in the commercial context.

\section{Web-Native Video Attributes and Aesthetics}

\section{"7/11:" Informality and Intimacy as Amateur Characteristics}

While the premise of " $7 / 11$ " is an iPhone recording of the pregame/sleepover festivities of Beyoncé and her girl squad at a hotel or apartment, it is in fact a record-company produced music video for a single in promotion of the Deluxe Box Set for the BEYONCÉ album and a line of merchandise. Musicologist Kai Hansen argues that for Beyoncé, "notions of her private self operate as integral to a representational strategy that crafts her persona through a continuous (re-) negotiation of the supposed synchronization of the artist's private and public lives." ${ }^{\prime 15}$ The intentionally presented seeming approachability of " $7 / 11$ " is a site for this renegotiation; what created the much discussed "carefree, casual vibes"16 of the video was the adoption of elements which characterize amateur video on YouTube, particularly informality, intimacy, and low tech and lighthearted productions. I argue the amateur elements of "7/11" act not only as signifiers to viewers' lives, but are indexed to genres of viewing with which social-media audiences are familiar on the same platforms on which " $7 / 11$ " circulated.

The locations featured in the video particularly play into the creation of intimacy. The camera finds Beyoncé and her dancers in places-and states of mess-you often are only in with people who are close to you: a clothes-strewn bedroom, a living room full of gifts, a cramped kitchen, a cluttered bathroom. In slightly better condition, they are the places where many vloggers, or 'first person' YouTubers film. ${ }^{17}$ The costuming contributes to the informal feel of the video; seemingly pulled from those piles in the bedroom, the wardrobe includes graphic sweatshirts, leggings, sports bras, and matching air-brushed men's briefs with the lyric "Smack It" across their butts, as if the friends took a multipack to the mall to have them done for the school talent show. 
This make-do aesthetic is carried out through the apparently low-tech set-up. There's an acknowledgement of the camera, from the very beginning when Beyoncé 'presses record,' through to the use of a selfie stick. A hair dryer is used to create movement for Beyoncé's tresses, a reference to the way devotees approximate the effect of large fans used in Beyoncé's concerts and music videos. The lightheartedness extends to the movement vocabulary, all performed with goofiness: her solo movement includes New Jack Swing moves like the running man and the sprinkler, twerking one butt cheek at a time with a smile, talking on a foot phone, and laughing on the floor after falling while jumping her left leg through a circle made by her right leg and left arm, attempting the tap move Over The Top. The group sections foreshadow the subsequent fan versions of this video, reminiscent of planning a dance with your friends at a sleepover, with moves repeated over several counts of eight, a pyramid, and lyrical echoes.

But this is not your best friend's childhood basement; this is a conglomeration of amateur signifiers elevated to the level of, well, Beyoncé. The locations are in fact fancy living spaces, edited together to seem like one place, without the tracking shots many YouTube dance videos use that show full venues. The homey fashion is for sale ${ }^{18}$ but it is paired with a $\$ 425$ visor, a $\$ 1,925$ Versace necklace, and a lace dress from Givenchy's 2011 resort collection. ${ }^{19}$ From the very first shot the footage is played with-rewound, repeated, sped up. Writing of the use of analogue video in digital culture, Jonathan Rozenkrantz asserts "the commodified moments to which we most eagerly look forward are no longer manifestations of a prospective imaginary, the utopia of all tomorrow's parties, but the retrospective joy of yesterday's parties made to look as if they played out decades ago." ${ }^{20}$ While "7/11"'s dancing has a nostalgic feel, I argue the adoption of amateur video aesthetics is a move about this very moment: it replicates the experience social media users have of watching the party they're not at unfold right now. Unlike on Snapchat or InstaStories, in " $7 / 11$ " there's never an actual amateur moment, but we still desperately want to be at that hangout, and through the amateur signifiers, imagine we could be.

\section{"The A-Z of Dance:" Web-Native Production Strategies}

The "A-Z of Dance" is firmly a dance video-a conceptual piece with dance at its center, performed with the desire to entertain. It is secondarily a piece of promotion for the media company i-D and the clothing brand Diesel Jeans; the fact that everyone wears denim is only salient when you've finished processing the content-the alphabetic list of moves and styles and its expertly danced entries, ranging from the fad dance 'Chicken Noodle Soup' to 'Vogue Hands' to 'Indian Bhangra.' The features of the video form a partial but indicative list of web-native video production. The list format, including alphabetic lists, have a long history in magazines, but the listicle and other formats have become characteristic of the internet, ${ }^{21}$ a fact the i-D A-Z videos have continued directly while also shaping a new video trend. ${ }^{22}$ "In the A-Z of Dance," the entries are 
enumerated by stylized onscreen text, possible even within YouTube's own editing program. The videos' main settings; a rooftop in the midst of a city scape, and a parking lot, reflect the web-video strategy of finding the best looking free place to shoot that has light and enough space. In addition, the casting mirrors dancer-run projects and collaborations by including YouTube-famous dancers like the Turf Feinz, Philip Chbeeb, Lil' Buck, and Ryan Heffington, and many dance styles known from social media, including finger tutting and the Harlem Shake meme. ${ }^{23}$

Despite being an ad, these components successfully created a web dance video and allowed it to circulate as such, though they're elevated: there's multiple shots and angles for each entry, and in addition to the outside spaces, there's also footage in a studio and black and white boxes. The extensive credits-another web-specific feature rarely seen on commercial content-reveals a huge cast, crew, and production team most YouTube-based dancers would not be able to afford or manage.

\section{"\#ICAN Kick It:" Sponsorship and Creative Control}

lan Eastwood's video is one of twelve dance videos set to A Tribe Called Quest's "Can I Kick It," sponsored by American Eagle as part of their \#ICAN campaign highlighting individuality. The videos, each lead by professional strata YouTube dancers, function as celebrity brand endorsement and a call for amateur entry for a competition. Sponsorships have become a major component of YouTube-native video as one important way content creators can make money or obtain resources for a specific project. ${ }^{24}$ The generic components or aesthetic of the content creator don't often change in these videos; brands choose specific YouTubers because they like their videos and think the product would fit well with the channel's audience. ${ }^{25}$

Sponsored campaigns place more agency with more and different people than topdown approaches. In this instance, \#ICAN is the campaign, but the prompt is specified by Eastwood through the choreography, setting, styling, and videographic style. In his video, the camera follows Eastwood and his Young Lions crew through his house, with different phrases unfolding as they travel through rooms discovering different dancers, finally ending in the garage. In contrast to precision choreography often seen in legacy advertisement, the movement is loose in the way the joints connect and balls move in sockets, and limbs hang and move with weight. There's freestyle and individuality within unison sections, and as is Eastwood's style, the movement is in playful communication with the song's lyrics and instrumentation. Though funded through promoting a large business, each \#ICAN video was unique, featured performance and videography styles endemic to YouTube, and was conceived of and carried out by YouTubers and their own teams. 


\section{"Mi Gente ft. Beyoncé:" Official Use of Fan Production}

Mashups are a type of video response that use collage and remix aesthetics to incorporate different types of content, generally already existing and often copyrighted. ${ }^{26}$ In June of 2017 J Balvin, and Willy William released a fairly standard music video for their hit song, "Mi Gente." ${ }^{\text {"27 }}$ In a reversal of typical Internet directionality, the official music video for the remix, released in late September, is a mashup comprised entirely of fan production posted to social media throughout the summer. The use of fan video functions promotionally in line with the 'one world' sentiment of "Mi Gente" (my people) and its bilingual, multi-national creators, demonstrating how widely liked and broadly played the song was, with videos taken in classes, with families, in clubs, with famous and everyday people, shot in different geographies and interpreted by various cultures.

In the music video, the visual amateurism of the fan clips is stressed and enhanced through the editing; the clip quality seems degraded through ripping, ${ }^{28}$ vertical videos remain unaltered or framed, ${ }_{1}^{29}$ and a faux-VHS tracking effect ${ }^{30}$ is overlaid throughout. Through editing, clips of many different web-native screen genres become an instance of commercial music video, with the wide differences in style, quality, and source obscured, ${ }^{31}$ elided into a single 'amateur' aesthetic. While highly successful as a videojust two days after its release it had almost 10 million views ${ }^{32}$ - this flattening indicates that some people operationalizing these genres don't actually understand their difference, or find them meaningless in the face of a still persistent, much longer running discourse of professional and amateur, where anyone not working for a major music label is considered amateur.

\section{Dance and Advertising: Adaptations to Web-Native Context}

Dance on the popular screen has always had a complicated but close relationship with the market and consumerism, whether in film, television, or music videos. This relation is most obvious when dancers are featured in advertising, where their creative and physical labor directly serves the bottom line. Advertising also provides dancers with large audiences, the largest some of them may ever have, and therefore provides key opportunities for dancers to broadcast their abilities, secure future employment, and spread movement innovations, both on television and online. While the video examples examined in this article replicate the core relation of dance and capital inherent in advertisement, in taking up new styles and platforms for circulation from web-native video, commercial content has also taken up some of the attending modes and tendencies of Internet production. This includes more integrated promotions, increased representation of marginalized communities, and close relationships to fan content.

In her book Black Social Dance in Television Advertising: An Analytical History, Carla Stalling Huntington focuses on the use of black social dance in advertising and its 
impact on the self-perception and consumption behavior of the viewers. In Huntington's analysis, the purpose of advertising is to get the viewer to engage in economic exchange by creating desire through accessible imagery; in the context of an advertisement featuring dance, this desire is the ability to dance, created through performance. She contends that dance has the power to sell goods and services beyond itself, and that commercials using black social dance implicitly connect consumer desire with a generalized envy of a perceived black mastery of dance. Further, Huntington notes that since the 1940s, dance-including black social dance-in the advertising context was performed primarily by white performers. Because of this she characterizes the use of black social dance in advertisement as an a-historical commercialization of long standing cultural practices, which enables companies to profit from the dance practices' cultural capital while disempowering black dancers and erasing the dances' communities of origin. While dancers featured in advertisements since the late 1990s have been more racially diverse, the critique of the commodification of the dance forms still stands.

In "Performing the Commodity-Sign: Dancing in the Gap" dance scholar Colleen Dunagan analyzes the ways in which Gap advertisements from 1998-2000 drew on signifiers and production aspects from Hollywood musicals to create stylized campaigns centered on 'product personality' at the nexus of clothing and the popular dancing body. The staging of social dance forms through filmic strategies contributed, Dunagan argues, to "framing these commercials as performances even as they work to produce a commodity-sign." ${ }^{33}$ Advertisers have long sought ways to make commercials more appealing to viewers, and dance has played a large role in amplifying the dimension of entertainment. Dance is currently in an extended moment of primacy, but it is particularly linked to the media forms being consumed online. This is especially important for online advertisers, since it is increasingly possible to skip, block, or click away from ads, which need to be particularly interesting to circumvent that impulse. Just as the Gap ads would have seemed more like other TV programming than like other commercials, online, advertisers mimic the aesthetics of user-generated content in their ads, blurring the difference between the commercial, the professional, and the amateur so as to fit into existing viewing practices on phones, tablets, or laptops.

To describe the emphasis on the entertainment factor over the hard sell, Dunagan utilizes Robert Goldman's nomenclature of a "not-ad," an advertisement that "has been designed to look as if it is not an ad, as if it has foresworn the agenda of ads." ${ }^{34}$ This maps well onto the examples I have presented; music videos are perhaps the pinnacle artform of 'not-ad' promotional material, and the two clothing ads circulate mostly innocuously as dance videos. The style and signs that are adopted are different between the YouTube videos and Dunagan's Gap commercials-forward-looking and 'amateur' rather than nostalgic for large-budget theater and film traditions-but the strategy is 
similar: to distract from the fact of the advertising and sell instead the entertainment presented by the video.

Much online commercial content has moved even further towards obscuring their marketing intention while promoting consumption. ${ }^{35}$ This often means eschewing advertising norms like framing copy. For example, the "A-Z of Dance" promotes the Jogg Jeans line by Diesel, but the product's features-material so flexible you can dance in jeans-are not mentioned in the three and a half minute video. I had to discover them through Google. ${ }^{36}$ This doesn't make the commercial-cum-dance video less effective promotionally; 'viral' campaigns often privilege creativity and viewer follow-up over explanatory messaging. Other legacy media advertising hallmarks, like the white space of an infinity cove-seen in everything from truck to Gap ads-are also absent from 'not-ad' videos meant for Internet platforms.

In 2007, Dunagan argued that the use of the all-white space in the Gap ads of the late 90s subverted advertising structure through its filmic possibilities. In the intervening years, the white space became connected to television advertising, while web-native videos center their subjects in the settings of home, studio, and street. As an example, Eastwood's loose, home-based "ICAN video" is in direct contrast to a GAP ad, "Bounce meet Bounce" which came out only a few weeks before. ${ }^{37}$ Made as a 30 second television and reroll ad, it has the same basic purpose as the American Eagle campaign-sell mass produced casual and leisure-wear-but features precisely choreographed unison movement focused on percussion, and was shot from above on a rig in a take on Gap's now iconic white space.

In that filmic space, Dunagan asserts that "the white backdrop becomes a metaphor for the body of the consumer, signifying that the consumer exists as a tabula rasa, an empty space or absence, until the individual/body dons the Gap apparel and assumes an identity." ${ }^{38}$ The shift out of the white box parallels a shift I observe in some brand's marketing strategies, which recognize that many people in the social media age have a strong sense of identity and are already performing and affiliating around it. So, in addition to the conventional wisdom that consumers are seeking "to attain the identity offered by purchasing the advertised product," ${ }^{39}$ consumers seek products that reinforce and fit within their identities. This shift is reflected in advertisements, too, as brands include people with whom a wider range of the viewing audience can affiliate.

Increased representation of people of color and other marginalized people is another important attribute of commercial content interfacing with Internet dancers. Though racial and economic factors still restrict a complete meritocracy, because the videos are made in conjunction with content creators, they rely less on casting agents and more on existing communities of practice. The 'cast' for Eastwood's "\#ICAN" video is his crew, Young Lions, with whom he has practiced and performed for several years. Among them are Black, Latino, Asian American, and white dancers, reflecting the range of 
identities and backgrounds of young men who live in Los Angeles and have pursued dancing. The circumstances of representation vary given the production; in the "A-Z of Dance" some casting choices were made, but the range of dance forms lead naturally to a range of dancers and their identities, while "Mi Gente"'s incorporation of fan videos lead to a representation of those fans who identified with the music. While the aspirational component of advertising is still very much there in terms of productwouldn't you like to have a Givenchy dress to romp around in, like Beyoncé?-I argue the consumer is no longer a blank space, but rather is looking to see themselves reflected. And somewhere in the A through $Z$ of dances, there's definitely a dance you know, and a dancer who looks or moves like you.

Commercial content using web-native video traits is in a multidirectional relationship with Internet production. While "Mi Gente" is the only video discussed in the article which directly included fan content, the others all invited or provoked fan responses. For example, the generic touchstones derived from home-made videos used in " $7 / 11$ " were further demonstrated when fans restaged elements of the music video. Similarly, the success of i-D's collaboration with Diesel has manifested in the production of noncommercial A-Z videos. A month after $\mathrm{i}-\mathrm{D}$ 's video, a Senegalese dance studio produced "The A-Z of African Dance," shot in various outdoor locations throughout Dakar. The video has accumulated 2.5 million views, a stark contrast to the channel's average view count of a few thousand per video. ${ }^{40}$ The 2017 " $\mathrm{A}-\mathrm{Z}$ of Beyoncé Dance" video, made by Australian fans, ends with the note "this project is a non-commercial tribute to the goddess that is Beyoncé,"41 perhaps at once referencing the source material and perhaps simultaneously stating a moral position. It is shot in a white space with colorful animations surrounding the dancers, and each entry has multiple interpretations. While clearly influenced by the $i-D$ video, the collaborators moved back toward the aesthetics of art screendance rather than the approximation of amateurism needed to attain the 'not-ad.' Exemplifying the folding and cyclical nature of Internet creation, these amateur and web-native videos are indebted to the commercial productions inspired by their predecessors, and in turn become part of the bank of innovation, which might be drawn from next.

\section{Selling Out vs. Getting Yours}

Despite the development of rich online spaces and communities of expression and innovation by marginalized people, most notably "Black Twitter," of structural discrimination manifesting in the arts through appropriation, unequal remuneration, and lack of credit to individuals or collectives with less visibility still pervade the creation and circulation of content on the Internet. ${ }^{43}$ Web and social media video brings to this history its own complications around directionality of influence, traceability, and crediting made possible by the technology and ethics of 'sharing' which can both tether and unmoor data and images from their sources. ${ }^{44}$ Appearing in 
commercial projects informed by web-native video, which pay and give practitioners credit and creative control is an important counter to invizibilization. However, given the historical trend of commodifying black, latinx, and queer dance forms for the promotion of white-owned corporations, it is understandable that, as Sherril Dodds notes, "within some fields of dance practice," appearing in commercials or other legacy media forms, "can be construed as a form of 'selling out."' ${ }^{\prime 4}$ On the other hand, the particularities of online video necessitate a nuanced analysis of the values of participation and mediation of popular dance practitioners in the social media age, which are unique because of the technology, the control of production, and video's ubiquity.

While the performers and creators of the videos discussed in this article are more varied in their racial and economic backgrounds than those still mostly in creative control of legacy media advertising, the bulk of the financial gain from the videos go to majority white owned large corporations-to YouTube, a subsidiary of Google; record companies and their executives; ${ }^{46}$ and clothing companies-based on movement derived almost exclusively from the collective and individual innovations of young people of color. The people directly involved in the videos are likely paid for their time, and videos posted on creators' channels may bring in some AdSense revenue but the dancers mostly benefit from the promotional force of the exposure and circulation of their image. The originators of the movements, dance forms, and videographic techniques used within the videos don't benefit directly at all.

In an article on video magazines created by b-boys in the 1990s, Mary Fogarty argues against the villainization of mediation in the Hip-Hop dance narrative, pointing instead to the ways B-boys used media agentively to gain access to the entertainment industry and to paying jobs. Fogarty describes Breaking's relationship with commodification and commercialization as "ambiguous," because while dance is used in advertising in order to sell products, it is itself "considered to be lacking a commodity exchange-value." Dodds echoes this idea in her assertion that popular dance sells-but not itself. In many cases where a critique is leveled against the commercialization or mediatization of popular dance, the dance is working to sell something else, whether a soft drink as in the Pepsi ads analyzed by Huntington, or a dance film or reality television show, as Dodds refers to when she remarks that viewers are hooked with popular dance but actually "'buy' into those visual commodities." 48 In her article "Black Teens Are Breaking The Internet And Seeing None Of The Profits," Doreen St. Felix argues that "intangible things like slang and styles of dance are not considered valuable, except when they're produced by large entities willing and able to invest in trademarking them.." ${ }^{\prime \prime 9}$ Through the use of popular dance and video genre markers in commercial production as shown in the examples here, it is clear that dance does have exchange value, and value recognized by large entities, though for their own financial gain. 
Even while profit-minded, this recognition from brands and larger media companies has contributed to an economy where it is increasingly possible for dance practitioners to support themselves. Through ad revenue, exposure to possible sponsors and employers, and as a platform for an increasing volume of dance content, YouTube creates the possibility of remuneration for people who may have had difficulty accessing capital through entertainment pursuits. Rather than foreclosing the possibility of participatory culture, Burgess and Green argue "the commercial drive behind and hype around YouTube may have produced the possibility of participation in online video culture for a much broader range of participants." ${ }^{50}$ As with Fogarty's analysis of the video magazines, for many popular dance practitioners today, it is highly esteemed for a dancer to be shown in a widely viewed mediated representation, if not in fact required either generically or economically. It could be argued that the shifts in the judgment of 'making it' versus 'selling out' is due to the fact that, in web-native video, dance is now one of the products being sold. In addition, participating in commercial content makes it more possible to make those videos through which it's more difficult to earn.

Dance videos and dance-centric content creators are in a slightly different situation than those who don't rely on music; it's more difficult for them to earn money from YouTube directly. Videos that contain copyrighted music cannot be monetized by the uploader without express permission from the artist or label, ${ }^{51}$ so videos with hit songs-often the most popular-cannot directly benefit from their view counts. Instead, these have to be exchanged; the viewers are simultaneously a sign of the value of the artist and one of the commodities that makes the artist of interest to future sponsors or gigs. Even the most well-known YouTube dance creators put together funding through merch, teaching, and alternate funding structures while waiting to be hired as dancers or choreographers.

Attention to the distinct layers of content within web-video is important, because not all financial opportunities are available to everyone. Amateur creators and pop culture innovators - often youth of color-who do not have the popularity to earn ad money on YouTube videos, who create on less monetized platforms like Instagram, or who come to viral fame through a limited amount of content have little access to remuneration, though they disproportionately contribute to movement and screen genre evolution. St. Felix points to an additional complication for creators, especially of viral content who are less likely to have lawyers and managers; uploaders share the ownership, reproduction, and distribution rights with the hosting platform..$^{52}$ Speaking of the dancer who runs the YouTube channel SheLovesMeechie, St. Félix argues "as prolific and internet-known as Meechie and his crew are, they are multiple steps removed from owning, in a tangible sense, their art, leaving them vulnerable to both YouTube's whims and to having their creativity lifted by outsiders. ${ }^{\prime \prime 3}$ Because of these 
terms of use, even amateur content is already commercial; the platforms remediate prior social stratifications while at the same time circulating innovation.

\section{Conclusion}

Popular dance displayed on the screen has long been the subject of necessary critiques surrounding the commodification of community-specific knowledges, often governed by structural discrimination. The analysis of commercial use of web-native videographic and dance styles is complicated by new opportunities for representation, remuneration, and creative control that come with the new platforms and modes of production. It is important to attend to the economics and power relations within different screen genres as current systems of funding sought by popular dance practitioners online continue and change long-standing modes of harnessing agency and capital.

While many popular dance content creators happily work within and shape Internetspecific screen dance conventions and communities, for some their output and metrics for success are also defined by desired engagement with brands and larger media companies, which was the predominate model of 'making it 'until very recently. These projects can bring dancers in contact with creatives they admire, and despite the reality of professional YouTubers, can bring social-media creators more closely in line with definitions of professionalism in the cultural imaginary which still sees all web-native production as "amateur." As popular dance practitioners imitate and innovate, Internetoriented brands and media companies adopt and adapt, leading to multi-directional movement of generic conventions, labor, and capital.

These videos circulating together therefore reflect the constant tension of popular dance and the market, where desires for money and mainstream success balance against those for respect, community, and innovation. This has long been the cycle of popular culture, though specific technologies have changed. Innovations get more pointedly traced and credited now than in the past as meme cataloguing and trend coverage become important facets of Internet journalism and user production, and so many more moments are archived to be discovered. But it remains to be seen if remuneration and structural support will follow, to what extent, and for whom.

\section{Biography}

Alexandra Harlig is a PhD Candidate in Dance Studies at The Ohio State University Department of Dance. Her dissertation focuses on the production, reception, and economics of popular dance on YouTube, intersecting with questions of race, genre, 
and intellectual property on the Internet. Her chapter "Communities of Practice: Active and Affective Viewing of Early Ballroom dances, the Charleston, and the Twist on the Popular Screen" appears in The Oxford Handbook of Dance and the Popular Screen.

Email: harlig.1@osu.edu

Website: readymadebouquet.wordpress.com

\section{Notes}

${ }^{1}$ Dodds, Dancing on the Canon, 64.

2 See Deuze, "Corporate Appropriation;" Hunter et al., Amateur Media; Jenkins, Convergence Culture; Meese, "It Belongs to the Internet."

${ }^{3}$ Hunter et. al, xiii.

${ }^{4}$ Burgess and Green, YouTube, 76.

${ }^{5}$ Beyoncé, "Beyoncé - 7/11." Reference format note: Because different versions of these videos exist on YouTube, and because whose channel these videos are published on is an important part of differentiating agency and advertising strategy, the videos are referenced with the channel name as the author.

${ }^{6}$ i-D. "The A-Z of Dance."

${ }^{7}$ Ian Eastwood. "\#ICAN Kick It"

${ }^{8}$ jBalvinVEVO. "J Balvin, Willy William-Mi Gente ft. Beyoncé"

${ }^{9}$ Announced on Beyoncé's Instagram account 1.

${ }^{10}$ See Edmond "Here We Go Again: Music Videos after YouTube."

${ }^{11}$ Hunter et. al, i

${ }^{12}$ Meese, "It Belongs to the Internet."

${ }^{13}$ See Gottschild, Digging the Africanist Aesthetic, Kraut, Choreographing Copyright, and Manning, Modern Dance/Negro Dance.

${ }^{14}$ Such genres include vlogging, unboxing videos, video game play-throughs, among many others. Dance specific genres include street-based freestyle videos (ex. Yak Films), which feature popular dance practitioners in city scapes; challenges or fad dances (ex. Running Man Challenge, Harlem Shake); concept videos: non-music video 
popular dance-centric videos that have a theme, narrative, or strong visual aesthetic. (ex. Willdabeast Adams and Janelle Ginestra); class videos shot at the end of classes and workshops at popular dance studios (ex. Those shot by Tim Milgram); and comedy or sketch dance videos like the 'Now Add a Dancer' series on TheDOMINICShow, where mundane tasks are transformed into dance prompts.

${ }^{15}$ Hansen, “Empowered or Objectified?," 166

${ }^{16}$ White, "Watch Beyoncé Dance"

17 "First-person" videos refer to those featuring one person in direct address to the camera, including cooking, beauty, and personality-based videos.

${ }^{18}$ Four of the shirts she wears in the video were sold by the extended Beyoncé brand, and lists were made of other purchasable or replicable items as many were affordable-leggings from Forever 21, for example. See Kokshanian.

${ }^{19}$ Wilson, "Wait, Did Beyonce Tease Brand New Merch."

${ }^{20}$ Rozenkrantz, "Analogue Video in the Age of Retrospectacle," 42.

${ }^{21}$ See Edidin, "5 Reasons" and Konnikova, "A List of Reasons"

${ }^{22}$ After the success of this video, i-D produced twelve more between spring 2014 and fall 2017, with various themes (beauty, hair, slang), five in collaboration with other brands. Other creators took up the format as well.

${ }^{23}$ See Bragin, "From Oakland Turfs to Harlem Shakes" for a critique of the Harlem Shake meme as a viral anti-blackness, another web-specific component.

${ }^{24}$ Many unaffiliated videos-makeup tutorials, home improvement, shopping haulsnonetheless feature branded products, so "\#notsponsored," has actually become an inside joke for many content creators both in description boxes and in the flow of onscreen speech.

${ }^{25}$ Sponsored videos also crucially appear on the content creator's own channel, marking the videos as their own work and putting it in the regular flow of YouTube views and the AdSense money that comes with them. See "YouTube Partner Program Overview."

${ }^{26}$ See Simonsen, "The Mashups of YouTube."

${ }^{27}$ jBalvinVEVO. "J Balvin, Willy William - Mi Gente (Official Video)."

${ }^{28}$ The image is further made fuzzy because all copyrighted or trademarked images are blurred, something seen frequently in YouTube videos but done here by the "Mi Gente" editor. 
${ }^{29}$ Media Studies scholar Andreas Treske notes "video's verticality refers to the amateurish act and response to the moment of experience, something that is not controlled and presumes to be witnessed." Treske, Video Theory, 135.

${ }^{30}$ Rozenkrantz writes of the use of VHS-tracking apps "VHS style' has become a prominent signifier of an obsessively retrospective media culture in which one is more likely to download an app to produce faux-grainy videos with one's iPhone than to watch a film on actual VHS, or to reflect on the technology that gave rise to those grains in the first place." Rozenkrantz, 41.

${ }^{31}$ Record label produced music videos rarely credit anyone, even the director. To be able to give credit of any kind for the videos included in "Mi Gente Remix" you have to recognize the contributors, or to look to write-ups about the video, where authors tracked down some of the celebrities and videos featured. See Kelly. "The Video for the Beyoncé Remix of 'Mi Gente.'

${ }^{32}$ On YouTube, 69 million views as of 9 Feb 2018.

${ }^{33}$ Dunagan, "Performing the Commodity-Sign," 17.

${ }^{34}$ Goldman, Reading Ads Socially, 155-201. Cited in Dunagan, "Performing the Commodity-Sign," 4.

${ }^{35}$ Dunagan, "Performing the Commodity-Sign," 4. There is always some indication that such a video is connected to a brand, whether noted in titles, descriptions, onscreen logos, or off-site paratexts like Instagram and Twitter posts sharing or discussing the video. The FTC and YouTube require disclosure of paid promotion. See YouTube, "Paid Product Placements."

${ }^{36}$ Contrast this with a 30 second Aéropostale web ad that ran as pre-roll on YouTube and was hosted on the brand's channel. It uses popular dance choreography but is more in line with legacy advertising, featuring music-video style quick editing of seven women dancing testing the limits of the jeans' flexibility ends with the framing copy "the only jean you need: Seriously Stretchy Jeans" splashed on the screen. Aéropostale, "Seriously Stretchy Jeans."

${ }^{37}$ Gap. "Bounce Meet Bounce."

${ }^{38}$ Dunagan, "Performing the Commodity-Sign, 18.

${ }^{39}$ Ibid., 7.

40 The Dance HALL, "A-Z OF AFRICAN DANCE." View count on YouTube as of 8 Feb 2018. In November 2017, they released an additional video, an alphabetic list featuring only Senegalese dance, which has circulated much less without the excitement and context of the much more popular i-D version. 
${ }^{41}$ The A-Z of Beyoncé Dance, "The A-Z of Beyoncé Dance."

${ }^{42}$ See Florini, "Tweets, Tweeps, and Signifyin;", Sharma, "Black Twitter?;" and Prasad "Beyond rights as recognition."

${ }^{43}$ This has been much discussed in the wake of the micro-video site Vine's death. See Daileda, "Let's not forget the black Vine stars;"Gaillot "Life after Vine" Giorgis, "Black Users on Vine."

${ }^{44}$ See Meese; Jenkins, Burgess, and Green, Spreadable Media.

${ }^{45}$ Dodds, "Values in Motion," 452.

${ }^{46}$ Beyoncé has her own company, Parkwood Entertainment, but her music is exclusively licensed to the Columbia Records division of Sony Music. It's unlikely that high level music artists are earning money directly from their videos though their success helps promote songs, tours, and future contracts.

${ }^{47}$ Fogarty, "Breaking Expectations," 449.

${ }^{48}$ Dodds, "Values in Motion," 452.

${ }^{49}$ St. Felix, "Black Teens."

${ }^{50}$ Burgess and Green, YouTube, 76.

${ }^{51}$ YouTube, "Video monetization criteria."

${ }^{52}$ YouTube, "Terms of Service," section 6.C; Instagram "Terms of Use," section Rights.1

${ }^{53}$ St. Felix, "Black Teens."

\section{References}

Aéropostale. "Seriously Stretchy Jeans from Aéropostale." YouTube. 20 July 2015.

American Eagle. "Contest Closed: Kick It With AEO \& DanceOn [Playlist]" YouTube. Updated 7 Sept 2017.

https://www.youtube.com/playlist?list=PLuOO4vzBIQcK8HIDNWQZ6oZr7NfD_ixCi

Beyoncé. “Beyoncé - 7/11." 21 Nov 2014. YouTube.

Beyoncé. Video Collage of Beyoncé Posing in Colorful Dress. Instagram. 28 Sept 2017. https://www.instagram.com/p/BZmx_nbH4BT/?hl=en 
Bragin, "From Oakland Turfs to Harlem Shakes: Hood Dance on YouTube and Viral Antiblackness." The Oxford Handbook of Screendance Studies. Ed. D. Rosenberg. New York: Oxford University Press, 2016. 537-556.

Burgess, Jean, and Joshua Green. YouTube: Online Video and Participatory Culture. Cambridge UK: Polity, 2009.

Daileda, Colin. "Let's not forget the black Vine stars that turned the app into an art." Mashable. 27 Oct 2016. https://mashable.com/2016/10/27/vine-black-userscreatives/\#UKLMDr3bxOqw

Deuze, Mark. "Corporate Appropriation of Participatory Culture." Participation and Media Production: Critical Reflections on Content Creation. Ed. N. Carpentier and S. Livingstone Newcastle upon Tyne, UK: Cambridge Scholars Publishers, 2008. 27-40.

Dodds, Sherril. Dancing on the Canon: Embodiments of Value in Popular Dance. New York: Palgrave Macmillan, 2011. https://doi.org/10.1057/9780230305656 . "Values in Motion: Reflections on Popular Screen Dance." Oxford Handbook of Dance on the Popular Screen. Ed. M Blanco Borelli. New York: Oxford University Press, 2014. 445-454.

Dunagan, Colleen. "Performing the Commodity-Sign: Dancing in the Gap." Dance Research Journa/39.2 (2007): 3-22. https://doi.org/10.1017/S014976770000019X

Edidin, Rachel, "5 Reasons Listicles Are Here to Stay, And Why That's Ok." Wired.com. 8 Jan 2014. https://www.wired.com/2014/01/defense-listicle-list-article/

Edmond, Maura. "Here We Go Again: Music Videos after YouTube." Television \& New Media 15.4 (2014): 305-320. https://doi.org/10.1177/1527476412465901

Florini, Sarah. "Tweets, Tweeps, and Signifyin': Communication and Cultural Performance on 'Black Twitter."' Television and New Media 15.3 (2014): 223-237. https://doi.org/10.1177/1527476413480247

Fogarty, Mary. "Breaking Expectations: Imagined Affinities in Mediated Youth Cultures." Continuum: Journal of Media \& Cultural Studies 26.3 (2012): 449-462. https://doi.org/10.1080/10304312.2012.665845

Gaillot, Ann-Derrick. "Life After Vine." TheOutline.com 16 Jan2018. https://theoutline.com/post/2941/vine-shutdown-one-year-later-christianagilles?zd=1

Gap. “Bounce Meet Bounce-Full Film.” 25 July 2017. YouTube.

Giorgis, Hannah. "Black Users on Vine: Celebrating Blackness 6 Seconds at a Time" The Guardian 17 May 2015. 
https://www.theguardian.com/commentisfree/2015/may/17/black-users-on-vinecelebrating-blackness-6-seconds-at-a-time

Goldman, Robert. Reading Ads Socially. London: Routledge, 1992.

Gottschild, Brenda Dixon. Digging the Africanist Presence in American Performance: Dance and Other Contexts. Westport, CT: Greenwood, 1996.

Hansen, Kai Arne. “Empowered or Objectified? Personal Narrative and Audiovisual Aesthetics in Beyoncé's Partition." Popular Music and Society40.2 (2017): 164-180. https://doi.org/10.1080/03007766.2015.1104906

Hunter, Dan, Roman Lobato, Megan Richardson, and Julian Thomas, Ed. Amateur Media: Social, Cultural, and Legal Perspectives. London: Routledge, 2013.

Huntington, Carla Stalling. Black Social Dance in Television Advertising: An Analytical History. Jefferson North Carolina: McFarland, 2011.

Ian Eastwood. "\#ICAN Kick It with lan Eastwood \& The Young Lions |"Can I Kick It" Tribe Called Quest" YouTube. 19 Aug 2017.

i-D. "The A-Z of Dance." 7 April 2014. YouTube.

. "A-Z Guides [Playlist]" YouTube. Updated 30 Nov 2017.

https://www.youtube.com/playlist?list=PLOXwHyzEvi7hjGN1Pqlj60uaTaugKtqvN

Instagram. "Terms of Use." Instagram.com. Updated 19 Jan 2013.

https://help.instagram.com/478745558852511

jBalvinVEVO. "J Balvin, Willy William - Mi Gente (Official Video)." YouTube. 29 June 2017.

. “J Balvin, Willy William-Mi Gente ft. Beyoncé" YouTube. 28 Sept 2017.

Jenkins, Henry. Convergence Culture: Where Old and New Media Collide. New York: New York University Press, 2006.

Jenkins, Henry, Sam Ford, and Joshua Green. Spreadable Media: Creating Value and Meaning in a Networked Culture. New York: New York University Press, 2013.

Kelly, Caitlin. "The Video for the Beyoncé Remix of 'Mi Gente' Is Jam-Packed with Recognizable Faces." Billboard.com. 29 Sept 2017.

https://www.billboard.com/articles/columns/latin/7981833/the-video-for-thebeyonce-remix-of-mi-gente-is-jam-packed-with

Kokshanian, Rita. "Fresher Than You: Pick Up the Pieces Beyoncé Wears in Her New '7/11' Music Video." InStyle.com. 24 Nov 2014. http://www.instyle.com/news/fresheryou-pick-pieces-beyonc-wears-her-new-711-music-video 
Konnikova, Maria. "A List of Reasons Why Our Brains Love Lists." NewYorker.com. 2 Dec 2013. https://www.newyorker.com/tech/elements/a-list-of-reasons-why-our-brainslove-lists

Kraut, Anthea. Choreographing Copyright: Race, Gender, and Intellectual Property Rights in American Dance. Oxford: Oxford University Press, 2015. https://doi.org/10.1093/acprof:oso/9780199360369.001.0001

Manning, Susan. Modern Dance/Negro Dance: Race in Motion. Minneapolis: U of Minnesota P, 2004.

Meese, James. "It Belongs to the Internet': Animal Images, Attribution Norms and the Politics of Amateur Media Production." M/C Journal, 17. 2 (Feb 2014).

http://journal.media-culture.org.au/index.php/mcjournal/article/view/782

Prasad, Pritha. "Beyond Rights as Recognition: Black Twitter and Posthuman Coalitional Possibilities." Prose Studies 38.1 (2016): 50-73.

https://doi.org/10.1080/01440357.2016.1151763

Rozenkrantz, Jonathan. Alphaville: Journal of Film and Screen Media 12 (Winter 2016): 39-58.

Sharma, Sanjay. "Black Twitter? Racial Hashtags, Networks, and Contagion." New Formations: A Journal of Culture/Theory/Politics 78.1 (2013): 48-64.

https://doi.org/10.3898/NewF.78.02.2013

St. Felix, Doreen. "Black Teens Are Breaking the Internet and Seeing None of The Profits." TheFader.com. 3 Dec 2015. http://www.thefader.com/2015/12/03/on-fleekpeaches-monroee-meechie-viral-vines

Simonsen, Thomas. "The Mashups of YouTube." NORDICOM Review. 34.2 (2013): 47-63. https://doi.org/10.2478/nor-2013-0053

The A-Z of Beyoncé Dance, "The A-Z of Beyoncé Dance." YouTube. 28 Mar 2017.

The Dance HALL, “A-Z OF AFRICAN DANCE." YouTube. 18 May 2014.

Treske, Andreas. Video Theory: Online Video Aesthetics or the Afterlife of Video. Bielefeld, Germany: Transcript Verlag, 2015. https://doi.org/10.14361/9783839430583

White, Caitlin. "Watch Beyonce Dance All Over the House in Just Socks and Underwear for the '7/11' Video." MTV.com. 21 Nov 2014.

http://www.mtv.com/news/2006141/beyonce-7-11-video/

Wilson, Gaby. "Wait, Did Beyonce Tease Brand New Merch in Her '7/11' Video?." MTV.com. 24 Nov 2014. http://www.mtv.com/news/2008145/beyonce-711-videotease-new-merch/ 
YouTube. "Terms of Service." YouTube. 9 June 2010.

https://www.youtube.com/t/terms

. "Paid Product Placements and Endorsements." Updated 4 Oct 2016.

https://support.google.com/youtube/answer/154235?vid=1-6357760771156732844005401040

. "Video Monetization Criteria." Accessed 9 Feb 2018.

https://support.google.com/youtube/answer/97527

"YouTube Partner Program Overview." Accessed 9 Feb 2018.

https://support.google.com/youtube/answer/72851 